\title{
Synthesis and Characterization of Bulky FSM with Interconnected Mesopore-Networks Using an HHP Method
}

\author{
Mari TAKIMURA, Hidezumi NAGATA, ${ }^{*}$ Yuki YAMASAKI, ${ }^{* *}$ Toshiyuki SUZUKI, ${ }^{* * *}$ \\ Yuichi IKUHARA**** and Atsushi NAKAHIRA* \\ Kyoto Institute of Technology, Goshokaido-cho, Matsugasaki, Sakyo-ku, Kyoto-shi, Kyoto 606-8585 \\ * Osaka Prefecture University, 1-1, Gakuen-cho, Sakai-shi, Osaka 599-8531 \\ ** Osaka Prefectural College of Technology, 26-12, Saiwai-cho, Neyagawa-shi, Osaka 572-8572 \\ ***Japan Fine Ceramics Center, 2-4-1, Mutsuno, Atsuta-ku, Nagoya-shi 456-8587 \\ **** The University of Tokyo, 7-3-1, Hongo, Bunkyo-ku, Tokyo 113-8656
}

\author{
HHP 法による連結したメソポアネットワークを有する FSM バルク体の合成と評価

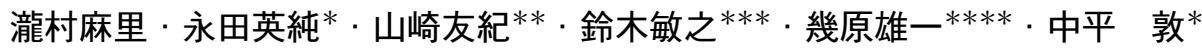 \\ 京都工芸繊維大学工芸学部物質工学科, 606-8585 京都市左京区松ヶ崎御所海道町 \\ *大阪府立大学工学部マテリアル工学科, 599-8531 堺市学園町 1-1 \\ **大阪府立工業高等専門学校工業化学科, 572-8572 寝屋川市幸町 26-12 \\ ***(財)ファインセラミックスセンター (JFCC)，456-8587 名古屋市熱田区六野 2-4-1 \\ ****東京大学大学院工学系研究科, 113-8656 東京都文京区本郷 7-3-1
}

\begin{abstract}
In this study, the synthesis of bulky FSM materials was attempted by a hydrothermal hot-pressing (HHP) method at relatively low temperatures. The obtained FSM bulks had dense microstructures without large voids and extremely high values of specific surface areas of over $1000 \mathrm{~m}^{2} / \mathrm{g}$. TEM observations showed that the bulks synthesized by this HHP method possessed a regular hexagonal arrangement of uniform mesopores and no amorphous phase at the interface between FSM grains, leading to bulky FSM bodies with interconnected mesopore-networks. As a result, dense bulky bodies with hexagonal structured mesopores and high values of specific surface areas could be obtained by this HHP method. These bulky FSM bodies are expected to be applicable as catalysts, adsorbents, sensors, electronics materials, and so on.
\end{abstract}

[Received February 17, 2006; Accepted April 19, 2006]

Key-words : Mesoporous silica, FSM, Hydrothermal hot-pressing, HHP, Dense microstructure, Interconnected mesopore-networks

1. Introduction

Mesoporous materials have regular hexagonal arrangements of uniform mesopores and high value of specific surface areas over $1000 \mathrm{~m}^{2} / \mathrm{g}$, although conventional porous materials such as activated carbon and silicagel have the micro-, meso-, and macropores. In general, mesoporous materials are synthesized using a surfactant as a template for introduction of mesopores. Thus, mesoporous materials are considered to be typical organic/inorganic materials. These mesoporous materials are expected to be useful for adsorbents and catalysts, and in addition, to be applicable as immobilizing agents for biomolecules, metal and semiconductor clusters, membranes for gas separation, and such as electronically and optically functional materials, for example. ${ }^{1)-3)}$ Recently, the application of mesoporous silica to a drug delivery system (DDS) was also attempted using its capability for accepting and delivering organic compounds. ${ }^{4}$ Diffusion behavior of occupied ibuprofen, which is antifebrile, as a guest in MCM-41 was reported. However, since powdered mesoporous materials were restricted in their practical application in many fields, bulks, coatings, and membranes of mesoporous silica are strongly desired.

For example, many results on synthesis of membranes of mesoporous materials by spin and dip coating etc. have been reported.5)-7) Synthesis of bulky mesoporous silica by conventional calcine methods and methods using a silicate as a binder are generally difficult because of the collapse of the mesopore structures and poor densification on sintering. In this study, development of synthesis approach for bulky mesoporous silica was attempted with the addition of water by a hydrothermal hot-pressing (HHP) method with a surfactant as a template. HHP methods were developed as a formation process of sedimentary rock. In HHP methods, it is possible to promote the solubility of particles and connect these particles at low temperatures of below $473 \mathrm{~K}$ for a short time by using actions of hydrothermal water under hydrothermal conditions. It has been reported that various inorganic materials can produce solid bodies from high-level radioactive-waste, ${ }^{8)-10)}$ for recycling as glass powder ${ }^{11)-14)}$ using HHP methods. Nakahira et al. ${ }^{15), 16)}$ reported that solidified Y-zeolites having high values of specific surface areas were successfully obtained by this HHP method. In this study, we report the results of synthesis of the bulky and dense mesoporous silica FSM bodies from FSM powder with and without a surfactant as a starting powder for HHP.

\section{Experiment}

\subsection{Synthesis of FSM powder}

FSM powder was synthesized as reported by Inagaki et al. ${ }^{17)}$ The silicate single layers of kanemite were condensed to form a three-dimensional silicate network during cation-exchange of $\mathrm{Na}^{+}$ions in the interlayer of kanemite for alkyltrimethylammonium ions (FSM powder with surfactant). Higher $\mathrm{pH}$ (over 11.5) at the cation-exchange process and the subsequent $\mathrm{pH}$ adjustment at 8.5 at the condensation process were best suited to the formation of mesoporous products. 


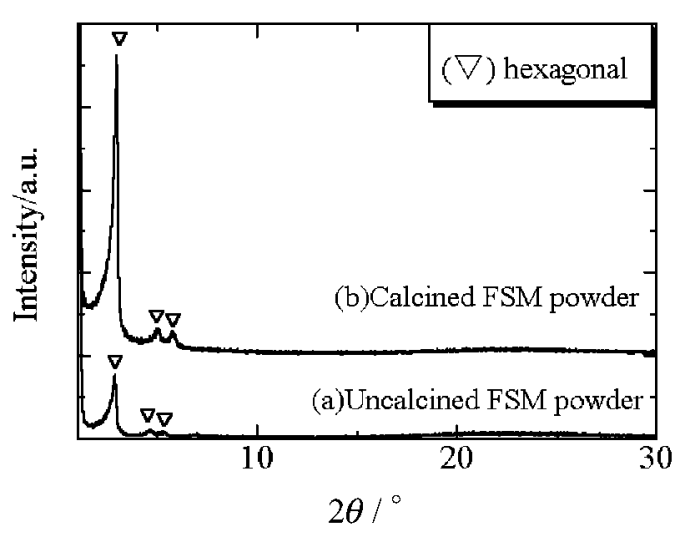

Fig. 1. XRD patterns of (a) uncalcined FSM powder (containing surfactant), (b) calcined FSM powder (without surfactant).

The obtained products were treated with calcination at $823 \mathrm{~K}$ for $7 \mathrm{~h}$ to remove surfactant (FSM powder without surfactant after calcination).

2.2 Synthesis of FSM bulk by HHP method

Both uncalcined FSM powder and calcined FSM powder were used as the starting powder for HHP. The mixture of powder and 20 mass $\%, 30$ mass $\%$, and 50 mass $\%$ of deionized water were set in a mold and mechanically pressed with a uniaxial pressure of $40 \mathrm{MPa}$ and subsequently heated at 383 to $443 \mathrm{~K}$ at a rate of $10 \mathrm{~K} / \mathrm{min}$ for $2 \mathrm{~h}$. Bulks prepared by HHP from uncalcined FSM powder were calcined at $823 \mathrm{~K}$ for $7 \mathrm{~h}$ in air to remove any surfactant inside FSM mesopores after HHP. To compare bulks prepared by HHP method, a uniaxially hand-pressed green body was prepared under a pressure of $40 \mathrm{MPa}$. In addition, green bodies were sintered at $1073 \mathrm{~K}$ and $1273 \mathrm{~K}$ at a rate of $5 \mathrm{~K} / \mathrm{min}$ for $2 \mathrm{~h}$ in air.

\subsection{Characterization}

The products were identified by a powder X-ray diffractometry (XRD, Rigaku RINT2500/Cu K $\alpha, 40 \mathrm{kV}, 50 \mathrm{~mA}$ ). Nitrogen adsorption isotherms, their specific surface area, and pore distribution of samples broken into a few pieces were measured with a gas adsorption apparatus (Japan-BEL, BELSORP 18PLUS-SPL). Microstructures were observed by transmission electron microscopy (TEM, JEOL, JEM2010/ SP) with an acceleration voltage of $200 \mathrm{kV}$. The observation of densification of bulky FSM bodies was done using a scanning electron microscope (SEM HITACHI, S-4500) with an acceleration voltage of $15 \mathrm{kV}$. The bulk densities of the products were calculated from their weight and the apparent volume. Differential thermal analysis and differential thermo gravimetric analysis (TG-DTA, TA-60, SHIMADZU) was measured for bulky FSM bodies.

\section{Results and discussion}

Figure 1 shows XRD patterns of uncalcined FSM powder and calcined FSM powder before HHP treatment. According to the XRD patterns, it was confirmed that both powders had mesoporous hexagonal structures, which were the same as those reported by Inagaki et al.

Figure 2 shows the XRD patterns of the bulk body prepared by HHP for calcined FSM powder without surfactant under $40 \mathrm{MPa}$ at $423 \mathrm{~K}$ for $2 \mathrm{~h}$ with 30 mass\% water content. Then, it was found that the mesoporous structures of the bulk obtained by HHP for the calcined FSM powder without surfactant had disappeared. In addition, Figure 2 shows the SEM image of the bulk prepared by HHP for the calcined
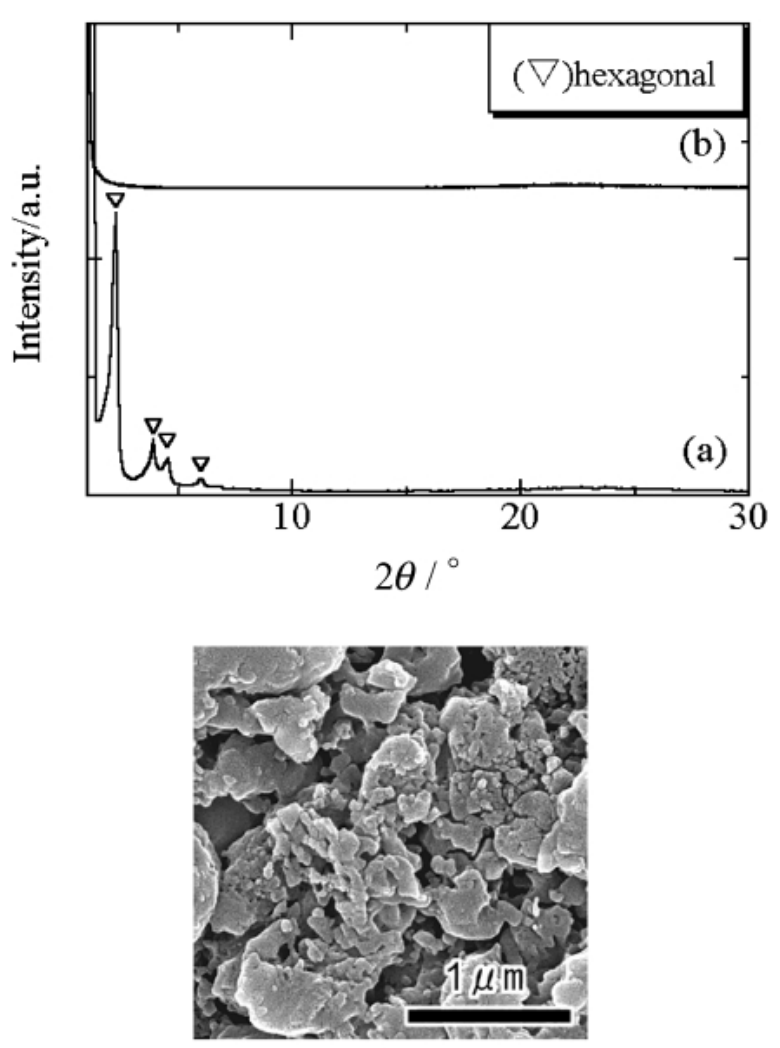

(c)

Fig. 2. XRD patterns of (a) calcined FSM powder, (b) bulk prepared by HHP from calcined FSM powder under $40 \mathrm{MPa}$ at $423 \mathrm{~K}$ for $2 \mathrm{~h}$, and (c) SEM image of bulk prepared by HHP from calcined FSM powder under $40 \mathrm{MPa}$ at $423 \mathrm{~K}$ for $2 \mathrm{~h}$.

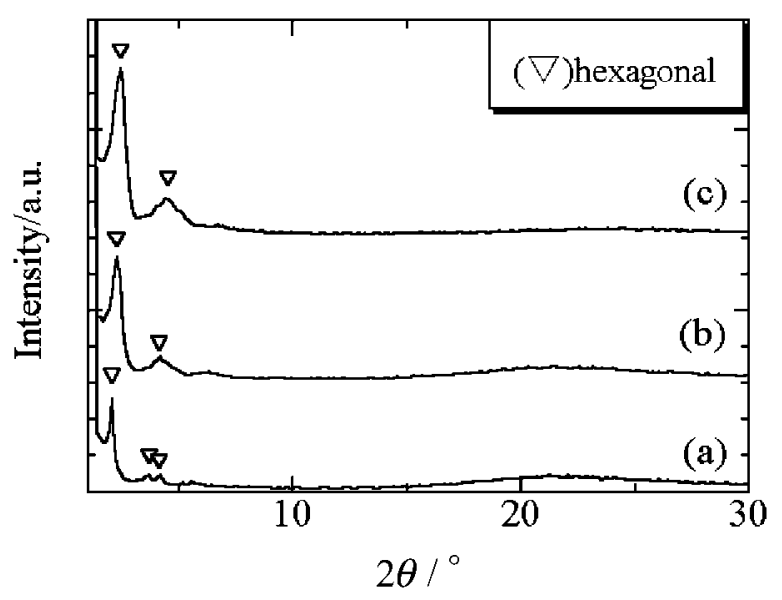

Fig. 3. XRD patterns of (a) uncalcined FSM powder, (b) bulk prepared by HHP from uncalcined FSM powder under $40 \mathrm{MPa}$ at $423 \mathrm{~K}$ for $2 \mathrm{~h}$, and (c) calcined bulk prepared by HHP from uncalcined FSM powder.

FSM powder without surfactant under a pressure of $40 \mathrm{MPa}$ at $423 \mathrm{~K}$ for $2 \mathrm{~h}$ with 30 mass\% water content. Thus, the microstructure of bulk prepared by HHP without surfactant contained many voids and the FSM could not be densified.

To retain the mesoporous hexagonal structures in the bulk bodies, we attempted to prepare FSM bulks by HHP with surfactant in the mesopores. Figure 3 shows the XRD patterns 


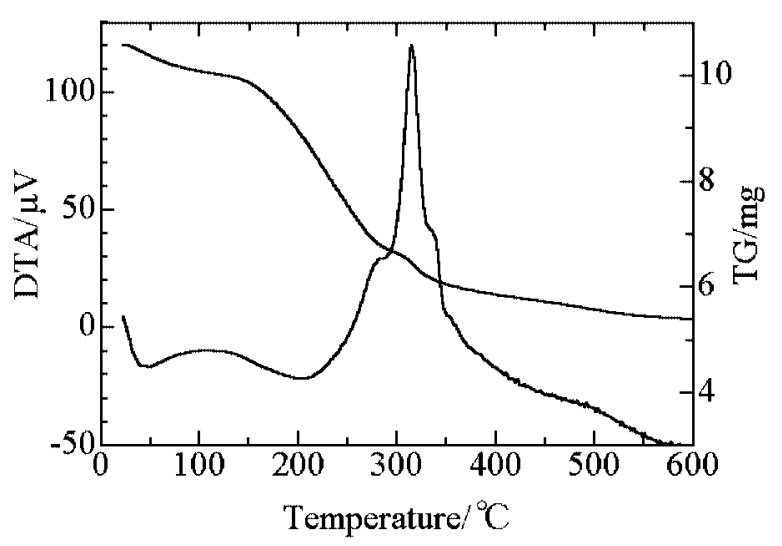

Fig. 4. TG/DTA curves of uncalcined FSM powder with surfactant.

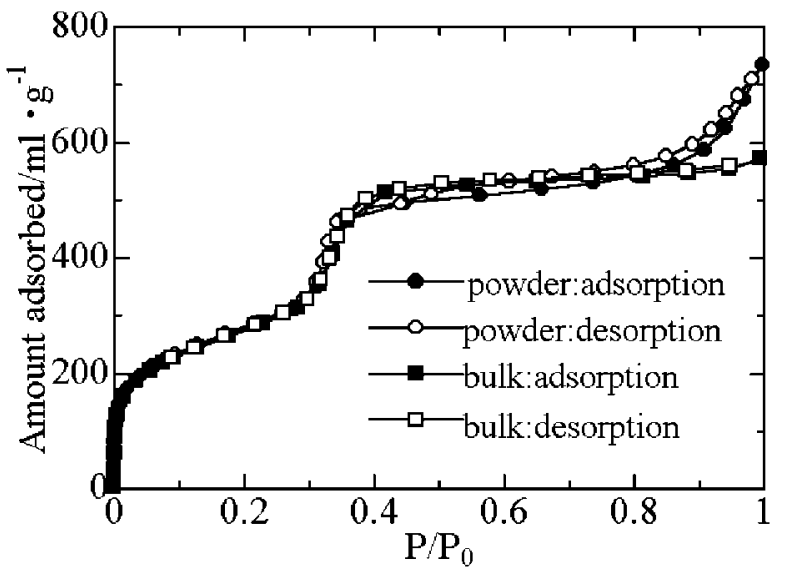

Fig. 5. Nitrogen adsorption/desorption isotherms of calcined FSM powder and calcined bulk densified by HHP from uncalcined FSM powder at $423 \mathrm{~K}$ for $2 \mathrm{~h}$.

of the uncalcined FSM powder, bulks prepared by HHP for uncalcined FSM powder at $423 \mathrm{~K}$ for $2 \mathrm{~h}$, and bulks calcined at $823 \mathrm{~K}$ for $7 \mathrm{~h}$ after HHP. According to the XRD patterns of (b) and (c), hexagonal peaks were confirmed in the mesoporous hexagonal structures. Thus, the mesoporous structures were retained in bulk bodies after HHP. The surfactant used in this study was pyrolyzed at $473 \mathrm{~K}$ to $583 \mathrm{~K}$ according to the results of TG-DTA (Fig. 4). These results suggest that the surfactant in uncalcined FSM powder plays an important role inside the mesopores on the densification under HHP treatment. Therefore, it appears that the existence of surfactant acting as a pillar resulted in the inhibition of collapse of the mesopores for FSM during HHP.

In various HHP synthetic conditions at temperatures of $383 \mathrm{~K}$ to $443 \mathrm{~K}$ with water contents of 20 to 50 mass $\%$, it was possible to obtain the bulks of FSM by HHP. However, at $473 \mathrm{~K}$ during the HHP reaction temperature, the mesoporous structures in obtained bulk diminished with the pyrolysis of surfactant inside mesopores.

Figure 5 shows nitrogen adsorption/desorption isotherms of (a) calcined FSM powder and (b) bulk calcined after HHP under $40 \mathrm{MPa}$ at $423 \mathrm{~K}$ for $2 \mathrm{~h}$. After calcination at $823 \mathrm{~K}$, the bulk prepared by HHP of uncalcined FSM powder with surfactant showed stepwise isotherms and a hysteresis derived from mesoporous structure as shows in Fig. 5 (b). These results suggest that mesoporous structures were retained after

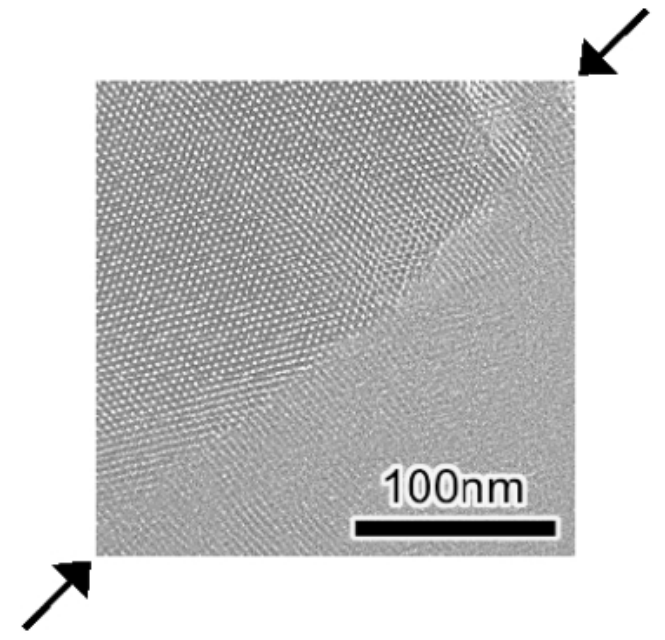

Fig. 6. TEM image of calcined bulk densified by HHP from uncalcined FSM powder at $423 \mathrm{~K}$ for $2 \mathrm{~h}$. Arrows show the boundaries between FSM grains.

Table 1. BET Values $\left(\mathrm{m}^{2} / \mathrm{g}\right)$ of Calcined Bulk Prepared by HHP from Uncalcined FSM Powder. The Calcined FSM Powder had a BET of $933 \mathrm{~m}^{2} / \mathrm{g}$

\begin{tabular}{|c|c|c|c|}
\hline & $\begin{array}{c}\text { Water content } \\
20 \mathrm{mass} \%\end{array}$ & $\begin{array}{c}\text { Water content } \\
30 \mathrm{mass} \%\end{array}$ & $\begin{array}{c}\text { Water content } \\
50 \mathrm{mass} \%\end{array}$ \\
\hline $110^{\circ} \mathrm{C}$ & $1192 \mathrm{~m}^{2} / \mathrm{g}$ & $1296 \mathrm{~m}^{2} / \mathrm{g}$ & $994 \mathrm{~m}^{2} / \mathrm{g}$ \\
\hline $150^{\circ} \mathrm{C}$ & $1024 \mathrm{~m}^{2} / \mathrm{g}$ & $1132 \mathrm{~m}^{2} / \mathrm{g}$ & $1111 \mathrm{~m}^{2} / \mathrm{g}$ \\
\hline $170^{\circ} \mathrm{C}$ & $1031 \mathrm{~m}^{2} / \mathrm{g}$ & $1054 \mathrm{~m}^{2} / \mathrm{g}$ & $1030 \mathrm{~m}^{2} / \mathrm{g}$ \\
\hline
\end{tabular}

※Calcined FSM powder: $933 \mathrm{~m}^{2} / \mathrm{g}$

HHP. In addition, isotherms of calcined FSM powder showed upward curvature near $P / P_{0}=1$ derived from macropores. In contrast, isotherms of calcined bulk by HHP for uncalcined FSM powder were flat. These results imply that after calcination at $823 \mathrm{~K}$, the macropores disappeared in the bulks solidified by HHP from uncalcined FSM powder. Consequently, the results for the nitrogen adsorption/desorption isotherms indicated the densification behaviors for FSM bulks treated by HHP.

Figure 6 shows a TEM image of calcined bulk prepared by HHP from uncalcined FSM powder. Mesoporous structure were observed by TEM for bulky FSM. Ordered mesopores with a pore diameter of approximately $2 \mathrm{~nm}$ were observed. Thus, the retention of mesoporous structures was confirmed by TEM. In addition, it was obvious that no amorphous phase existed at the boundaries of the FSM grains. Therefore, these TEM observations suggest that the FSM mesopores were connected through grain boundaries for calcined bulk densified by HHP for uncalcined FSM powder.

Table 1 showed BET values $\left(\mathrm{m}^{2} / \mathrm{g}\right)$ of calcined bulk by HHP from uncalcined FSM powder. The obtained bulk prepared by HHP under various conditions showed a significantly high value of BET of over $1000 \mathrm{~m}^{2} / \mathrm{g}$. In addition, $\operatorname{BET}\left(\mathrm{m}^{2} / \mathrm{g}\right)$ of calcined bulk densified by HHP from uncalcined FSM powder was higher compared with the FSM powder. These results reveal the possibility that bulks with high BET values and well-ordered mesopores could be obtained by 


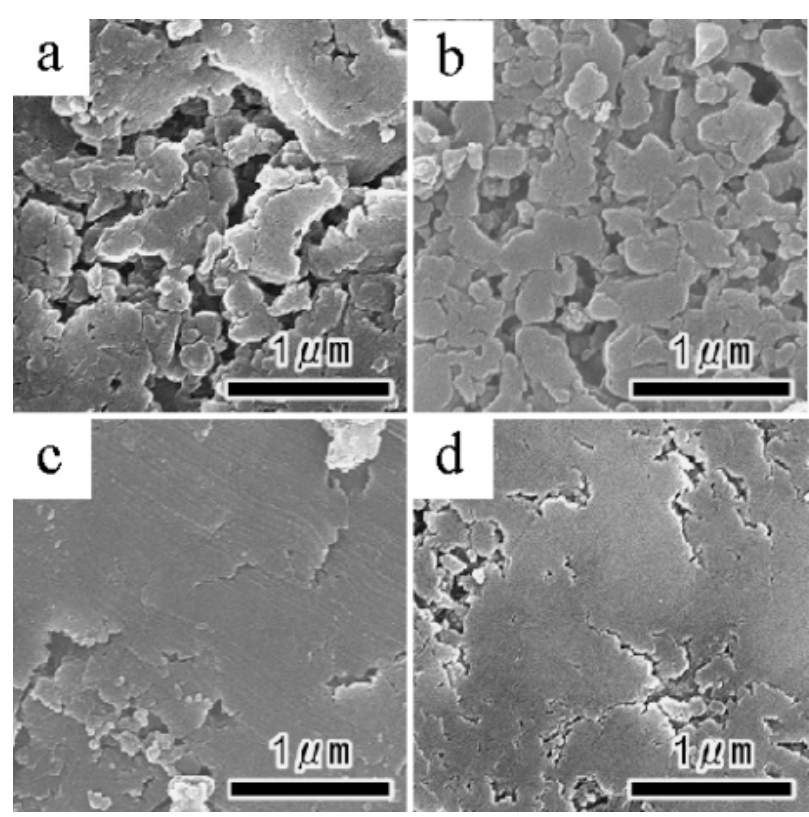

Fig. 7. SEM images of (a) green body, (b) sintered body at $1273 \mathrm{~K}$, (c) cross-section of bulks obtained by HHP from uncalcined FSM powder under $40 \mathrm{MPa}$ at $423 \mathrm{~K}$ for $2 \mathrm{~h}$, (d) calcined bulk prepared by HHP from uncalcined FSM powder.

HHP since residual unreaction phase in pores during HHP had disappeared. Consequently, the densification for FSM powder may be due to dissolution-precipitation process on HHP.

Cross-sections of bulks obtained by HHP from uncalcined FSM powder are shown in Fig. 7. The green bodies and sintered bodies had many voids. Bulks obtained by HHP from uncalcined FSM powder and calcined bulk prepared by HHP from uncalcined FSM powder showed flat surfaces and dense microstructures. It was obvious that bulks synthesized by HHP were sufficiently densified. Although the density of the green bodies from calcined FSM powder was $0.89 \mathrm{~g} / \mathrm{cm}^{3}$, FSM bulk sintered at $1073 \mathrm{~K}$ and at $1273 \mathrm{~K}$ had densities of 0.73 and $1.15 \mathrm{~g} / \mathrm{cm}^{3}$, respectively. Correspondingly, the densities of the solidified bulks with large BET values prepared by HHP were almost consistently in the range of 1.25 to $1.30 \mathrm{~g} / \mathrm{cm}^{3}$. According to the XRD results, the hexagonal peaks for sintered FSM bulks at $1073 \mathrm{~K}$ and at $1273 \mathrm{~K}$ had disappeared, leading to the collapse of the mesoporous structures. As mentioned above, in contrast, FSM bulk prepared by HHP, possessed mesopores as well as FSM powder. These results imply that solidified bulky mesoporous FSM, possessing interconnected mesopore-networks was synthesized at significantly low temperatures of below $473 \mathrm{~K}$. Although it is considered that the surfactant in uncalcined FSM powder played the role of a pillar inside the mesopores during HHP treatment, the effects of the surfactant on densification during HHP are still under detailed investigation.

\section{Conclusion}

In this study, bulky and dense mesoporous silicas (FSM) with a mesoporous structure were successfully synthesized prepared by HHP. The obtained bulks by HHP using uncalcined FSM powder were observed to be densified by the dissolution-precipitation process. The existence of a surfactant in HHP was effective in the densification process because in the bulk prepared by HHP from calcined FSM powder, densification was not observed. In addition, the bulks obtained by HHP using uncalcined FSM powder retained mesoporous hexagonal structures and a high value of BET of over 1000 $\mathrm{m}^{2} / \mathrm{g}$. It was considered that the surfactant in uncalcined FSM powder played the role of a pillar inside the mesopores during HHP treatment. The HHP method is a sustainable process and a useful method for synthesis of bulky mesoporous materials because of the low temperatures of below $473 \mathrm{~K}$ and the use of water as a solvent. These bulks of mesoporous silicas prepared using the HHP process are expected to be widely applicable to various new and existing fields.

Acknowledgement This work was in part supported by RITE program, 2006.

\section{References}

1) Eliseev, A. A., Napolskii, K. S., Lukashin, A. V. and Tretyakov, Y. D. Yuri D., Journal of Magnetism and Magnetic Materials, Vol. 272-276, pp. 1609-1611 (2004).

2) Chen, W., Cai, W., Zhang, Z. and Zhang, L., Chemistry Letters (2001).

3) Fukuoka, A., Higashimoto, N., Sakamoto, Y., Sasaki, M., Sugimoto, N., Inagaki, S., Fukushima, Y. and Ichikawa, M., Catalysis Today, Vol. 66, pp. 23-31 (2001).

4) Vallet-Regi, M., Ramila, A., del Real, R. P. and PerezPariente, J., Chem. Mater., Vol. 13, pp. 308-311 (2001).

5) Yang, H., Kuperman, A., Coombs, N., Mamiche-Afara, S. and Ozin, G. A., Nature, Vol. 379, pp. 703-705 (1996).

6) Lu, Y., Ganguli, R., Drewien, C., Anderson, M., Brinker, C., Gong, W., Guo, Y., Soyez, H., Dunn, B., Huang, M. and Zink, J., Nature, Vol. 389, pp. 364-368 (1997).

7) Miyata, H., Suzuki, T., Fukuoka, A., Sawada, T., Watanabe, M., Noma, T., Takada, K., Mukaide, T. and Kuroda, K., Nature Materials, Vol. 13, pp. 651-656 (2004).

8) Yamasaki, N., Yanagisawa, K., Kanahara, S., Nishioka, M., Matsuoka, K. and Yamazaki, J., J. Nucl. Sci. Technol., Vol. 21, pp. 71-73 (1984).

9) Yanagisawa, K., Nishioka, M. and Yamasaki, N., Am. Ceram. Soc. Bull., Vol. 64, pp. 1563-1567 (1985).

10) Mori, K., Katakura, M. and Yamasaki, N., Royoc. Ist Inter. Conf. Solvo-Thermal Reactions, pp. 150-150 (1994).

11) Hosoi, K., Kawai, S., Yanagisawa, N. and Yamasaki, N., J. Mater. Sci., Vol. 26, pp. 6448-6452 (1991).

12) Yanagisawa, K., Nishioka, M. and Yamasaki, N., J. Mat. Sci., Vol. 24, pp. 4052-4056 (1989).

13) Ioku, K., Kai, T., Nishioka, K., Yanagisawa, K. and Yamasaki, N., Phosphorus Res. Bull., Vol. 1, pp. 161-161 (1991).

14) Yamasaki, N., Kai, T., Nishioka, M., Yanagisawa, K. and Ioku, K., J. Mat. Sci. Lett., Vol. 11, pp. 233-234 (1992).

15) Nakahira, A., Murakami, T., Onoki, T., Hosoi, K. and Hashida, T., J. Am. Ceram. Soc., Vol. 88, pp. 1334-1336 (2005).

16) Nakahira, A., Takezoe, S. and Yamasaki, Y., Chemistry Letters, Vol. 33, No. 10, pp. 1400-1401 (2004).

17) Inagaki, S., Koiwai, A., Suzuki, N., Fukushima, Y. and Kuroda, K., Bull. Chem. Soc. Jpn., Vol. 69, pp. 1449-1457 (1996). 